\title{
The Role of Support Systems for Success of Underrepresented Students in Communication Sciences and Disorders
}

\author{
Akiko Fuse \\ Brooklyn College/The City University of New York, afuse@brooklyn.cuny.edu \\ Michael Bergen \\ Brooklyn College/The City University of New York, mbergen@brooklyn.cuny.edu \\ DOI: doi.org/10.30707/TLCSD2.3Fuse
}

Follow this and additional works at: https://ir.library.illinoisstate.edu/tlcsd

Part of the Curriculum and Instruction Commons, Higher Education and Teaching Commons, Other Education Commons, Other Teacher Education and Professional Development Commons, Scholarship of Teaching and Learning Commons, and the Student Counseling and Personnel Services Commons

\section{Recommended Citation}

Fuse, Akiko and Bergen, Michael (2018) "The Role of Support Systems for Success of Underrepresented Students in Communication Sciences and Disorders," Teaching and Learning in Communication Sciences \& Disorders: Vol. 2: Iss. 3, Article 3. DOI: doi.org/10.30707/TLCSD2.3Fuse

Available at: https://ir.library.illinoisstate.edu/tlcsd/vol2/iss3/3

This Scholarship of Teaching and Learning Research is brought to you for free and open access by ISU ReD: Research and eData. It has been accepted for inclusion in Teaching and Learning in Communication Sciences \& Disorders by an authorized editor of ISU ReD: Research and eData. For more information, please contact ISUReD@ilstu.edu. 


\title{
The Role of Support Systems for Success of Underrepresented Students in Communication Sciences and Disorders
}

\author{
Abstract \\ There is limited representation in Communication Sciences and Disorders (CSD) professions of \\ individuals from diverse populations. This study examined the relationship among CSD students' degree \\ of financial, emotional/moral, and academic support. The relationship between role models and \\ admissions outcomes was also assessed. It explored how support received by CSD students differs by \\ racial/ethnic backgrounds. A survey was completed by 57 alumni of an undergraduate CSD program, \\ revealing information about participants' backgrounds, support characteristics, and other factors. The \\ study 1) highlighted the importance of emotional/moral and financial support, 2) revealed reduced access \\ to financial and academic role models among alumni from diverse backgrounds, and 3 ) demonstrated the \\ impact of support in academic outcomes and graduate admissions. Establishing strong emotional/moral \\ support systems and role models with more extensive educational backgrounds is a key to academic \\ success in CSD. Finding a university program in which one can maintain a sense of belonging is critical \\ for retention of students. The study suggests that graduate programs offer multidimensional supportive \\ environments which provide both financial assistance and mentorship programs with access to role \\ models for students from underrepresented minorities, so they can achieve successful graduate \\ admissions leading to a career in the field of CSD.
}

\section{Keywords}

diversity, academic success, admissions, retention, speech-language pathology, communication sciences and disorders

\section{Cover Page Footnote}

This study was supported by a grant from the Dean of the School of Humanities and Social Sciences of Brooklyn College. I also would like to thank my colleague, Natalie Schaeffer for her feedback and the students, Melissa Calandra, Kara Hayden, and Krysteena Alloggio for their assistance with this project. I also would like to thank Howard Spivak, for his expert guidance on the statistical analysis.

This scholarship of teaching and learning research is available in Teaching and Learning in Communication Sciences \& Disorders: https://ir.library.illinoisstate.edu/tlcsd/vol2/iss3/3 


\section{Introduction}

United States (U.S.) Census Bureau data (2012) revealed that more than one-third of residents belong to culturally and linguistically diverse (CLD) populations, with projections suggesting that this number will increase to more than half of the population by 2044 (Colby \& Ortman, 2015). Cultural and linguistic diversity involves a number of factors: for example, language, race, ethnicity, gender identity, age, and religion. Cultural diversity often coincides with linguistic diversity, which is defined by the variations of speech and linguistic characteristics such as dialect, and/or the ability to speak more than one language or dialect (American Speech-Language-Hearing Association [ASHA], 2017b). An increasingly diverse population has coincided with an increase in multilingual homes: $20 \%$ of the population over the age of five speaks a language other than English at home (U.S. Census Bureau, 2013). These statistics contrast substantially with membership data of ASHA, which reported that $8 \%$ of its members identified themselves as belonging to a racial or ethnic minority group (ASHA, 2017a). Of those, 5.3\% of members identified their ethnicity as Hispanic or Latino, which is significantly below the $17.4 \%$ of the U.S. population (Colby \& Ortman, 2015). The lack of diversity in ASHA also extends to gender, with $4.7 \%$ of ASHA members identifying as being male (ASHA, 2017a). By the end of 2017, only $6 \%$ of members indicated they met the ASHA definition of bilingual service provider. This group speaks 78 languages other than English, and 64\% are Spanish-language service providers (ASHA, 2018). As such, there is great demand for speech-language pathologists (SLPs), audiologists, and bilingual clinicians from underrepresented groups (Council of Academic Programs in Communication Sciences and Disorders [CAPCSD] and ASHA, 2015; Kritikos, 2003; Saenz, Wyatt \& Reinard, 1998).

The New York City (NYC) metropolitan region presents a worthy example of the increasingly diverse population of the U.S.; the city exhibits rich culturally, linguistically, and ethnically diverse populations, and houses the institution where this current study was conducted. Moreover, NYC has a large number of school-aged children identified as "English Language Learners" (ELLs), representing more than 160 different home languages which contribute to the linguistic diversity of NYC. The top languages spoken by ELLs in NYC public schools include Spanish (61.8\%), Chinese (14.2\%), Bengali (4.2\%), Arabic (4.2\%), Haitian Creole (2.3\%), Russian (2.1\%), and Urdu (1.9\%) (NYC Department of Education, 2015). The obvious impact of this growing linguistically diverse population combined with a not-quite-diverse group of communication sciences and disorders (CSD) professionals (ASHA, 2018) raises questions about the availability and accessibility of those who are skilled in providing culturally and linguistically appropriate services. The situation in NYC, with a diverse population coinciding with a shortage of similarly diverse CSD service personnel, serves as a microcosm to demonstrate a key deficiency seen nationally. A substantial percentage of NYC ELL students $(21.6 \%)$ are identified as having disabilities and are receiving special education services (NYC Department of Education, 2015). This raises questions about potential misdiagnoses of students with CLD backgrounds, consistent with concerns raised previously (ASHA, 2017b). There is, therefore, a great continuing demand for CSD services provided by those who can properly assess and treat a client who speaks a language other than American English (ASHA, n.d.).

\section{Issues of Diversity in Graduate Programs and Professions in CSD}


University programs in CSD have not kept pace (ASHA, 2016b) with the trend towards increased diversity in higher education in the U.S. (U.S. Department of Education, 2013). ASHA membership has historically lacked diversity and is changing at a slow pace. As previously stated, the U.S. Census data (2013) revealed that $27.6 \%$ of the population were of a racial minority, while ASHA (2017a) reported only $8 \%$ of its membership of similarly diverse backgrounds. Gardner (2008) suggested that there is a "normative type of "mold' that has persisted" (p.126) in graduate and doctoral programs. In the case of CSD, as seen in the demographics of the current ASHA member reports, this normative mold would be comprised of female (95.3\%), white (92\%), and monolingual providers (94\%) (ASHA, 2017c). This differs from the increasing ethnic, cultural, and linguistic diversity seen in the US (ASHA, 2016b; Litosseliti \& Leadbeater, 2013). Those underrepresented CLD students who are not fitting into this "mold" may be discouraged from pursuing a CSD career (Gardner, 2008).

Two facts have highlighted the need to increase diversity in the CSD professions: the varying linguistic communicative abilities of a diverse population served by CSD professionals, and the lack of diversity amongst ASHA members. Clients and their family members may feel a sense of kinship with an individual of the same cultural and/or ethnic background, particularly if s/he is additionally familiar with their native language and can communicate needs freely without fear of being judged negatively (Harry, 2002). In order to address the void seen amongst professional ranks, it is important to first examine diversity within the academic programs and to identify those barriers which may limit recruitment and retention of CLD students who will ultimately populate the profession. The demographic report indicates a small increase of minorities enrolled in CSD programs in recent years. For example, the percentage of minority students enrolled in SLP programs had been $13.6 \%$ (2010-2011) and modestly increased to $15.8 \%$ (2012-2014) and later $17.11 \%$ (2014-2015) in more recent years. Similarly, enrollment of minority students in AuD programs actually slightly dropped from $10.3 \%$ (2010-2011) to 9.8\% (2014-2015). ASHA (2002) established a three-year Focused Initiative on Culturally and Linguistically Diverse Populations. Graduate programs in CSD were subsequently asked to evaluate their programs for successful recruitment, retention, and career transition strategies in order to increase the number of underrepresented minority students. Since onset of this initiative in 2002 (ASHA, 2002), proportions of Hispanic/Latino membership more than doubled (from $2.5 \%$ in 2002 to $5.3 \%$ in 2017), Black/African American membership increased (from 2.1\% in 2002 to $3.5 \%$ in 2017) and White membership decreased from 95.1\% to 92\% (ASHA, 2017a) in the same timeframe. However, male membership continued to decrease from 1997 (8.3\%) and 2002 (6.9\%) to 2017 (4.7\%, ASHA, 2017a). While these changes reflect a trend towards increased diversity in the professions, they are slow and well below the rates at which CLD groups are represented in the general population. A limited diversity increase has been documented from 2002 to 2015 (ASHA, 2016a), and there remains a discrepancy in the amount of diversity when comparing the student population in undergraduate and graduate CSD programs (CAPCSD and ASHA, 2018). In order to address this discrepancy, those needs and barriers which may hinder potential graduate school candidates must be identified and then considered when devising recruitment strategies and retention measures (CAPCSD and ASHA, 2015; Saenz et al., 1998). ASHA (2013) identified a number of factors which may deter CLD graduate candidates from success, such as financial barriers, graduate admissions requirements which often include standardized tests (i.e., GRE), and lack of diversity in the target programs. The admissions processes of CSD graduate programs are quite competitive (CAPCSD and ASHA, 2015), typically requiring a high grade-point average 
(GPA) and GRE score in addition to strong letters of recommendation (Polovoy, 2014). These requirements may become more challenging to minority students, especially those who present with low socioeconomic status (SES) and/or first-generation college students who may have limited financial resources and academic preparedness (John \& Stage, 2014; Simon, 1993; Spencer \& Castano, 2007), which may adversely impact graduate admission outcomes (Forrest \& Naremore, 1998). For those students who are not well prepared academically, demands of the graduate program may result in higher dropout rates. Limited financial resources may additionally present barriers by curtailing the number of graduate school applications and making important academic supports such as tutoring and tuition/housing costs, unachievable. The GRE has been shown to have a bias against minority students and those of lower SES; therefore a GRE requirement may provide an unintended barrier for certain students (Spencer \& Castano, 2007). With an ethnically and culturally homogeneous student body in CSD graduate programs (Chang, Sharkness, Hurtado, \& Newman, 2014; Winkle-Wagner \& McCoy, 2016), students who are not part of the mainstream culture may not be attracted to the professions. These complex factors present great challenges to recruitment and retention of individuals from diverse backgrounds in CSD graduate programs and professions (Forrest \& Naremore, 1998).

\section{Role Models}

Empowerment is crucial for minority and CLD students in higher education, since academic programs are not always designed to meet the specific needs (e.g., limited financial resources and academic preparedness) of such students and support them throughout their academic career (Winkle-Wagner \& McCoy, 2016). Role models are vital and have a powerful influence on an individual's development, beginning in childhood (Hurd, Zimmerman, \& Xue, 2009).

Developing affiliations with peers and teachers from their own or other underrepresented backgrounds, such as mentor-mentee relationships, would provide a positive impact and support for underrepresented students for academic success (John \& Stage, 2014; Winkle-Wagner \& McCoy, 2016). Previous research describes the important role of parents and close family members as role models for children and adolescents (Drummond, Senterfitt, \& Fountain, 1999; Hurd et al., 2009). While college students may seek a role model who is based in an educational setting, many instead prefer family members as their career role models (Karunanayake \& Nauta, 2004; Solomon, 1997). The lasting power of a role model was also previously reported in research on older students. College students have an average of four different career role models, regardless of their ethnic backgrounds, and those role models include friends, teachers, and celebrities. Role models have different kinds of influence and can provide emotional and/or moral support such as encouragement, guidance, and help in making decisions (Nauta \& Kokaly, 2001). In particular, family role models can have a long-lasting impact on academic success. Research revealed that family attitudes towards education and parental involvement are highly influential on academic success (Serbin, Stack, \& Kingdom, 2013; Zhang, Hsu, Kwok, Benz, \& Bowman-Perrott, 2011).

Previous research stated that when students choose non-family members as role models, they tend to select someone of the same race (Karunanayake \& Nauta, 2004; Solomon, 1997). Interestingly, Tan (1995) showed that African American students preferred a role model with the same ethnic background compared to the Asian American students, indicating different ideals towards role models. While there is variability across members of any group and one should refrain from 
making assumptions about specific individuals based solely on this data, there are, however, implications for student success based upon the availability of individuals who students may be more or less likely to adopt as role models. It was suggested by John and Stage (2014) that minority-serving institutions would be a discrimination-free, supportive environment by identifying role models such as faculty of the same backgrounds (John \& Stage, 2014; Thomas, Willis, \& Davis, 2007).

\section{Barriers to Graduate Education}

Socioeconomic status (SES) is reportedly one of the biggest predictors of academic and career success (American Psychological Association, 2012; Serbin, et al., 2013). Students with a high SES background tend to outperform those of low SES backgrounds (Smeding, Darnon, Souchal, Toczek-Capelle, \& Butera, 2013), possibly due to disparities in accessibility to resources and opportunities (Spera, Wentzel, \& Matto, 2009). When students have financial pressures and stress associated with lengthy work schedules, they can consume hours which might otherwise be used to focus on academics (Greene \& Maggs, 2015). Related pressures can affect retention and increased diversity in the professions (Chang et al., 2014). Chang et al. (2014) reported a large, homogenous student population, and a significantly lower retention rate of Black and Hispanic or Latino students than White/Caucasian or Asian students in college programs leading to STEM professions. Similar to Science, Technology, Engineering, and Mathematics (STEM) programs, CSD academic programs require graduate education and an increasingly competitive admissions process (CAPCSD and ASHA, 2015; Polovoy, 2014). According to data from CAPCSD and ASHA (2015), CSD graduate school admission often requires a high grade point average (GPA), Graduate Record Examinations (GRE) scores, strong letters of recommendation, and well-rounded experiences (e.g., research, extracurricular and volunteer activities) to enhance students' applications (Polovoy, 2014). Lower SES status has also been associated with fewer college applications, which could reduce the likelihood of acceptance. Even upon graduate program acceptance, student decisions for choosing a school may be based on tuition or other financial factors, which may make it less likely to attend one's 'first choice' school (Association for the Study of Higher Education, 2007). This may contribute to disproportionately lower representation of individuals from CLD backgrounds in CSD programs.

In addition to being competitive, CSD graduate programs often require of students a lengthy time commitment. Master's programs in SLP usually require at least 2 years of full-time study to complete while clinical audiology doctoral programs consume 3-4 years of full-time study (ASHA, 2016c). Including undergraduate coursework and, in some cases, post-baccalaureate coursework which may be prerequisite to graduation admission, this can reflect a commitment of 6-9 years of full-time college study prior to eligibility for professional employment. This timeframe presents a challenging period in which students are often unable to obtain employment for several years, which can increase financial barriers, particularly for those of low SES. This phenomenon is increased not only for minorities in institutions which are predominantly white, but also for those in minority-serving institutions (John \& Stage, 2014). These factors may limit representation of students from CLD populations in the professions (Henry, 2006) and result in ethnic, cultural, and SES homogeneity in the student populations (Winkle-Wagner \& McCoy, 2016).

The goal of the present study was to identify the factors which may contribute to success for students from CLD backgrounds in the field of CSD. More specifically, it examined the 
relationship of the following factors between the groups of students from non-CLD and CLD backgrounds: 1) role models, 2) financial support for education received from family and academic outcomes (i.e., GPA), 3) emotional/moral support and academic outcomes (i.e., GPA) and/or graduate admissions results, and 4) academic support and academic outcomes (i.e., GPA) and/or graduate admissions results.

It is hypothesized that 1) alumni with CLD backgrounds had fewer role models who completed formal higher education within their family than those from the non-CLD group, 2) alumni from CLD backgrounds had reduced financial support compared to non-CLD alumni and the group of alumni who received lower tuition support demonstrated lower academic outcomes (i.e., GPA), and 3) alumni who have a greater emotional/moral support system and/or academic support during college demonstrate better academic outcomes (i.e., GPA) and/or more successful graduate admissions.

\section{Methods}

\section{Participants}

A survey was distributed to 347 alumni who had graduated from a specific undergraduate CSD program within 5 years of the time of survey distribution. This program is located in a university within NYC that is known for its diverse student population. The college is fed by richly diverse populations in the communities of NYC surrounding the campus. Sixty-two individuals responded to the survey, and only data pertaining to the completed questions $(N=57)$ were included. All participants have at least a bachelor's degree; 13 alumni from non-CLD groups and 1 alum from CLD group works as an SLP or audiologist. 
Table 1

Demographics - Age Distribution

\begin{tabular}{|c|c|c|c|}
\hline Age range & $\frac{\frac{\% \text { of total }}{\text { participants }}}{(n=57)}$ & $\frac{\% \text { of CLD }}{\frac{\text { Group }}{(n=28)}}$ & $\frac{\% \text { of non-CLD }}{\underline{\text { Group }(n=29)}}$ \\
\hline 20 - 25 years old & $65 \%$ & $57 \%$ & $72 \%$ \\
\hline 26 - 30 years old & $21 \%$ & $18 \%$ & $24 \%$ \\
\hline $31-40$ years old & $9 \%$ & $14 \%$ & $4 \%$ \\
\hline $41+$ years old & $5 \%$ & $11 \%$ & $0 \%$ \\
\hline Mean age & & years old & 25 years old \\
\hline
\end{tabular}

Table 2

Demographics - Gender Totals

\# CLD Group \# non-CLD Group

$\begin{array}{lll}\text { Male } & 3 & 1\end{array}$

$\begin{array}{lll}\text { Female } & 25 & 28\end{array}$ 
Table 3

Demographics - Linguistic Background Distribution

$\begin{array}{lcc} & \begin{array}{c}\frac{\% \text { of }}{\text { Monolingual }} \\ \frac{\text { Participants }}{2}\end{array} & \frac{\% \text { of Multilinguals }}{\underline{\text { Participants }}} \\ \text { Total participants } & 53 \% & 47 \% \\ \text { CLD Group } & 54 \% & 46 \% \\ \text { non-CLD Group } & 41 \% & 59 \%\end{array}$

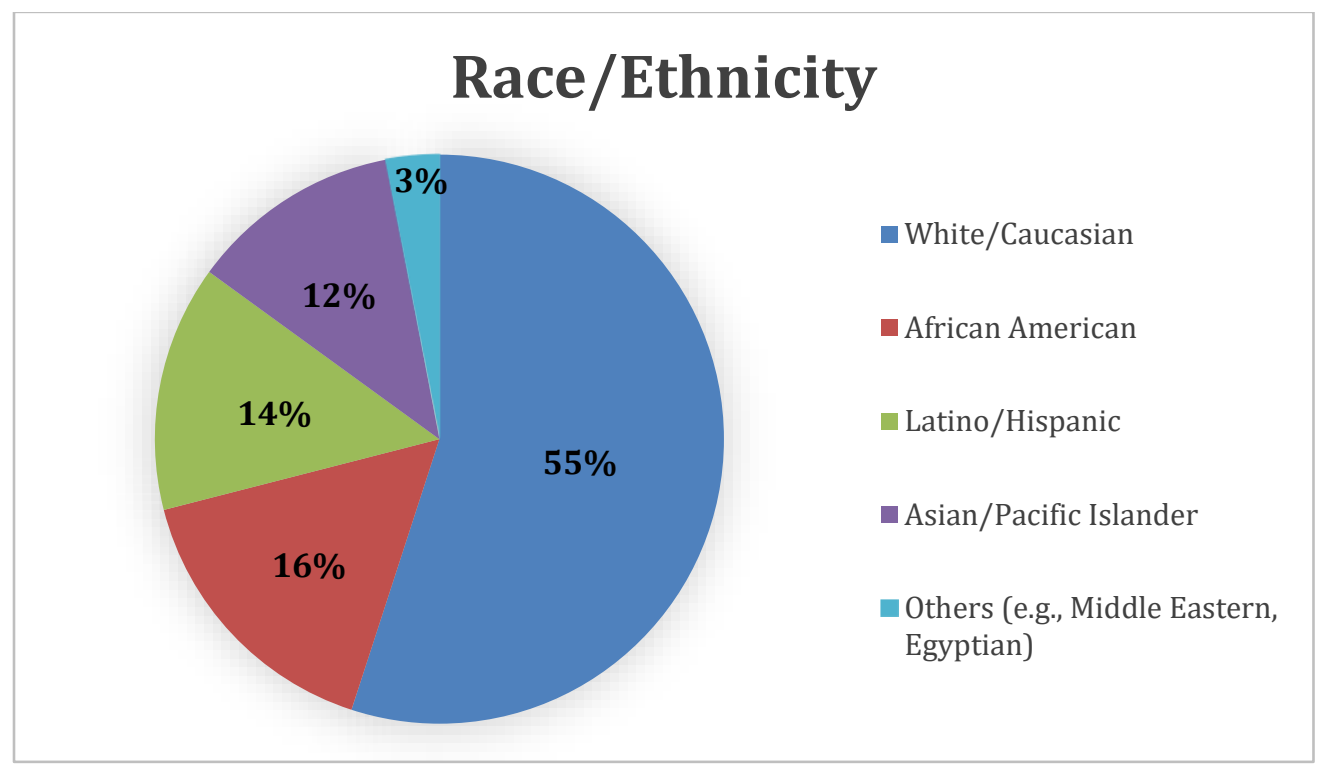

Figure 1. Distribution of participant race/ethnicity

\section{Materials}

The survey was designed to obtain information about participants' backgrounds (i.e., age, gender, language, race/ethnicity, education, academic outcomes, graduate admissions, household income, highest educational backgrounds, who earned the highest degree, family support for attending graduate school, financial support for education, emotional/moral support, academic support, and role model; See Appendix, the survey questions). The survey incorporated items that pertained to alumni experiences in an undergraduate CSD program at a specific institution such as career plans, access to advisement and service, perceptions of college, and their experiences. It consisted of items which included semi-closed-ended questions, closed-ended questions, open-ended questions, multiple choice questions (i.e., select one, select all and 4- to 8-point Likert-type scale), and ranking questions (scale of 0-5). Prior to distribution, a version of the survey was provided to a total of 10 undergraduate and graduate students to obtain input for validity. Additionally, 
feedback obtained from a focus group of students and alumni which preceded the study was reflected in the draft of the survey questions. There were no experimental manipulations to the survey questions; they were all self-report questions. The survey questions for background information (e.g., race and ethnicity, language, financial status, education) were adapted from the 2010 U.S. Census (2010) and modified to address the data pertinent to the research questions. The remaining questions were developed after review of survey instruments and the literature that presented information on college students' lives and experiences, including graduate admissions (Cornell University Division of Budget and Planning, n.d.; Pace \& Kuh, 1998; Steffani \& Slavin, 1997).

\section{Procedures}

The data were collected via an online survey which was distributed to the participants via a webbased survey tool, SurveyMonkey (www.SurveyMonkey.com). Prior to distribution, the Principal Investigators (PIs) obtained approval from the Institutional Review Board of the PIs' institution. Participants were provided with a link to the survey via email. They were allowed to skip questions or return to them at a later time, being provided with an unlimited amount of time to complete the survey. Once participants submitted the survey, they were unable to return to change their answers or to take the survey again. The survey was confidential, as no names or related identifying information was collected.

\section{Results}

\section{Data Analysis}

Descriptive and inferential statistics were used to determine racial/ethnic group tendency across variables. Mann-Whitney $U$ statistical test, the nonparametric alternative to the independent $t$ test, was administered to compare differences between two independent groups (Fay \& Proschan, 2010). The data, such as that associated with ethnicity, is categorical data which is used to create two groups: non-CLD and CLD. Assuming the sample was not normally distributed, the MannWhitney U statistical test was selected as the most appropriate option (Hollingsworth, Collins, Smith, \& Nelson, 2011). The results of the analyses were reported, including effect size.

In the analysis, non-CLD and CLD groups as well as financial, emotional/moral, and/or academic support, served as the independent variables (IVs). Seven dependent variable (DV) groups were associated with the following information about students: the highest level of education (by mother, by father, and in the household), financial (i.e., tuition) support received or anticipated

receiving, the amount of emotional/moral, GPA as well as graduate admission outcomes (see Table 4). 
Table 4

Data Analyzed for the 4 Hypotheses: Independent (IVs) and Dependent Variables (DVs)

\begin{tabular}{|l|l|l|}
\hline & IV & DV \\
\hline 1) Role models & CLD vs. non-CLD & $\begin{array}{l}\text { mother's, father's, and the highest level of education } \\
\text { in the participant's household. } \\
\text { GPA }\end{array}$ \\
\hline $\begin{array}{c}\text { 2) Financial } \\
\text { support }\end{array}$ & \begin{tabular}{l} 
CLD vs. non-CLD \\
\cline { 2 - 3 }
\end{tabular} & tuition support \\
\hline $\begin{array}{c}\text { 3) Emotional/ } \\
\text { moral support }\end{array}$ & $\begin{array}{l}\text { CLD vs. non-CLD } \\
\text { amount of } \\
\text { emotional/moral } \\
\text { support }\end{array}$ & amount of emotional/moral support \\
\hline $\begin{array}{c}\text { 4) Academic } \\
\text { support }\end{array}$ & $\begin{array}{l}\text { sought and/or } \\
\text { received academic } \\
\text { help }\end{array}$ & GPA, graduate admissions \\
\hline
\end{tabular}

In order to test the role of family role models, educational background was used because previous research indicates that role models for children and adolescents are usually close family members (Hurd et al., 2009), serve as academic role models (Hurd et al., 2009; Karunanayake \& Nauta, 2004) and have a positive impact on their academic success (John \& Stage, 2014; Winkle-Wagner $\&$ McCoy, 2016). Moreover, children tend to follow the same path as family members who are serving as their academic role models, and literature shows a link between parents' educational backgrounds and their child's educational levels (Haveman \& Smeeding, 2006; Spera et al., 2009). Further, mothers who served as role models during the subject's elementary school years remain role models for an extended period, and this influence can last longer than that of fathers (Drummond, et al., 1999). Therefore, the current study compared the highest educational backgrounds of immediate family members (mothers vs. fathers, as well as the entire household).

\section{Family Educational Backgrounds as Role Models}

The highest level of education within the participant's household was compared between non-CLD and CLD groups (see Figure 2). Statistical analyses indicated that when the non-CLD participants' mother's highest level of education (Non-CLD: $M d n=3$, Bachelors, masters and above), was compared with those of CLD backgrounds (CLD: $M d n=1.5,1=$ high school or less, $2=$ some college education less than associate degree), there was a significant difference between the two groups $\left(U=263, p=.016 ; \mathrm{y}^{2}=.103\right)$. 


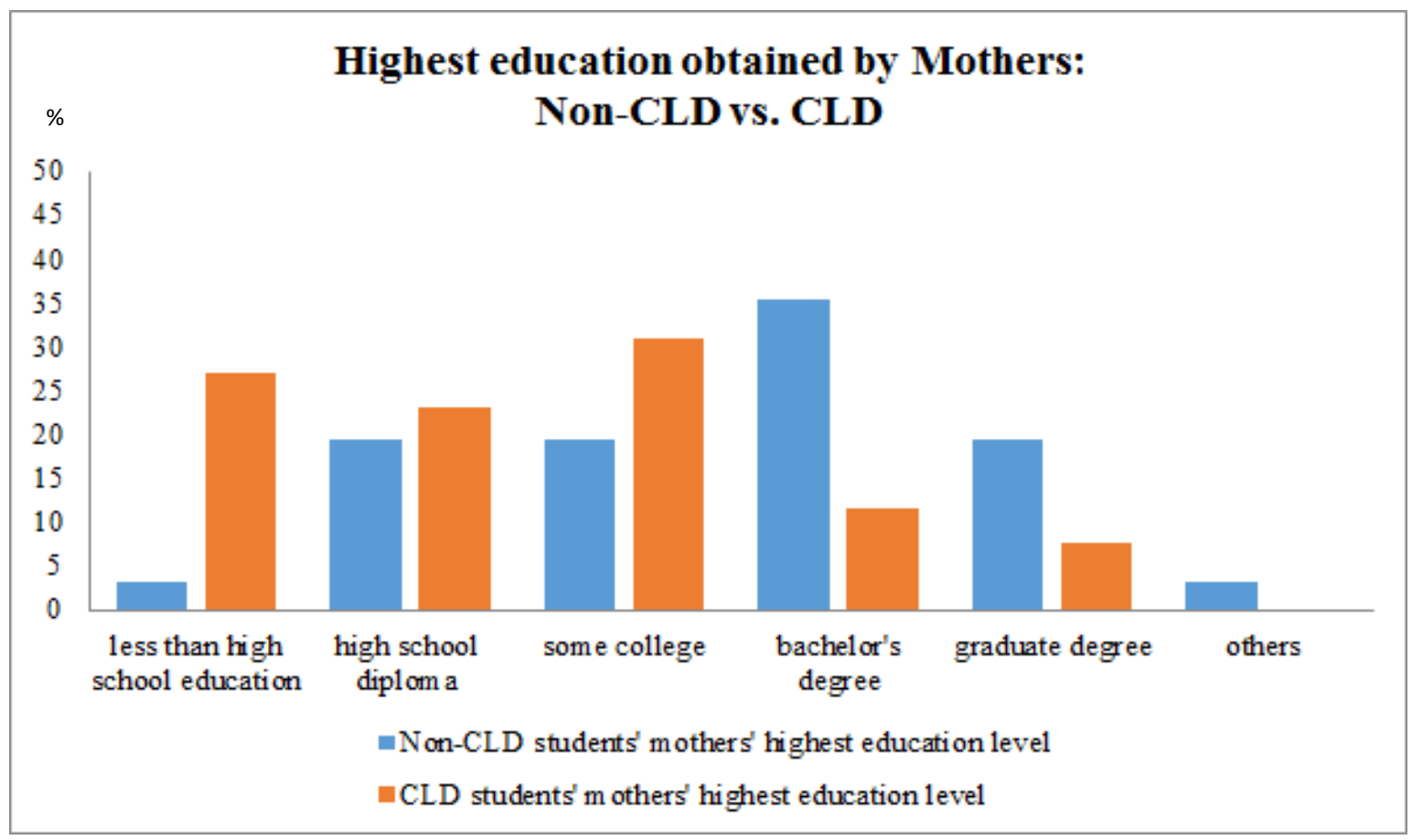

Figure 2. The highest level of education obtained by mothers: A comparison of non-CLD and CLD groups

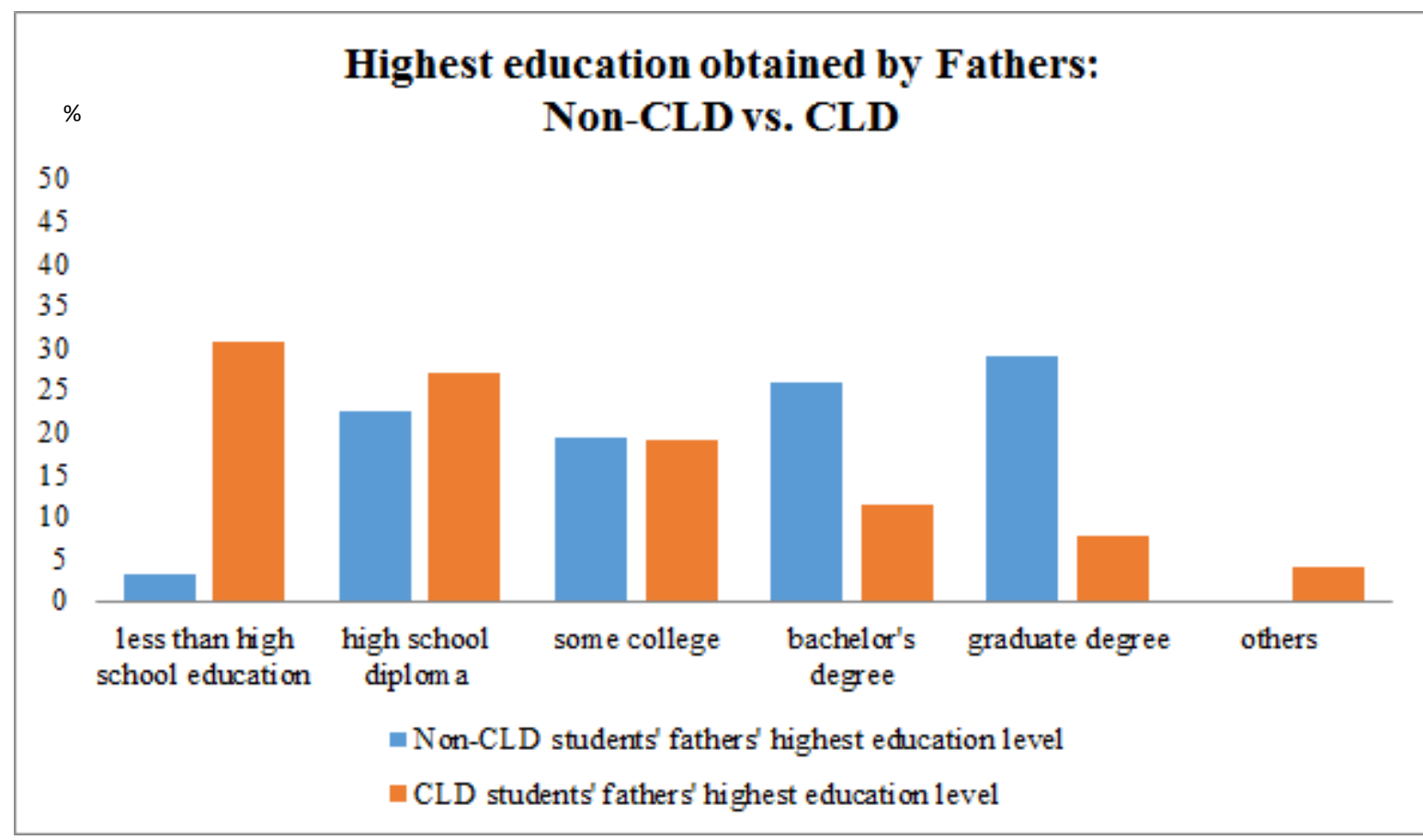

Figure 3. The highest level of education obtained by fathers: A comparison of non-CLD and CLD groups 
When participant father's highest level of education (Figure 3) was compared between these two groups, there was a significant difference between the participants with CLD backgrounds ( $M d n$ $=1$, high school or less) and non-CLD others ( $M d n=3$, bachelor's, master's and above, $U=231.5$, $\left.p=.003 ; \mathrm{n}^{2}=.157\right)$. These results indicate that both mothers and fathers of the non-CLD participants indicated significantly higher educational backgrounds than those of participants with CLD backgrounds. Mothers and fathers of those from the non-CLD group had more bachelor and graduate degrees, and fewer instances of achievement below high school level than the respective parents of the CLD group. Additionally, the mothers of the CLD students had a higher percentage of obtaining "some" college education than the mothers of the non-CLD students, suggesting possible withdrawal of enrollment prior to completion. These results indicate the limited potential for parents to serve as academic role models for CLD students as opposed to non-CLD students.

As seen in Figure 4, a bachelor's degree or higher was obtained by someone within the household of most participants. Furthermore, CLD participants had fewer family members with higher academic background than non-CLD participants (Non-CLD: $M d n=2$, master's and above; CLD: $M d n=1$, bachelor's degree, $\left.U=269, p=.020 ; \mathrm{y}^{2}=.099\right)$. It should be noted that the highest level of education in the CLD alumni's household was earned by either the alumni themselves, or a sibling in many cases, whereas one-third of individuals with the highest level of education from the non-CLD group was earned by someone other than the alumni themselves or a sibling. Additionally, a comparison of GPA between these two groups indicated that the alumni from nonCLD backgrounds reported significantly higher GPAs $(M d n=3.8, M=3.73)$ as compared to alumni with CLD backgrounds $\left(M d n=3.4, M=3.44, U=169.5, p=.001 ; \mathrm{y}^{2}=.195\right)$.

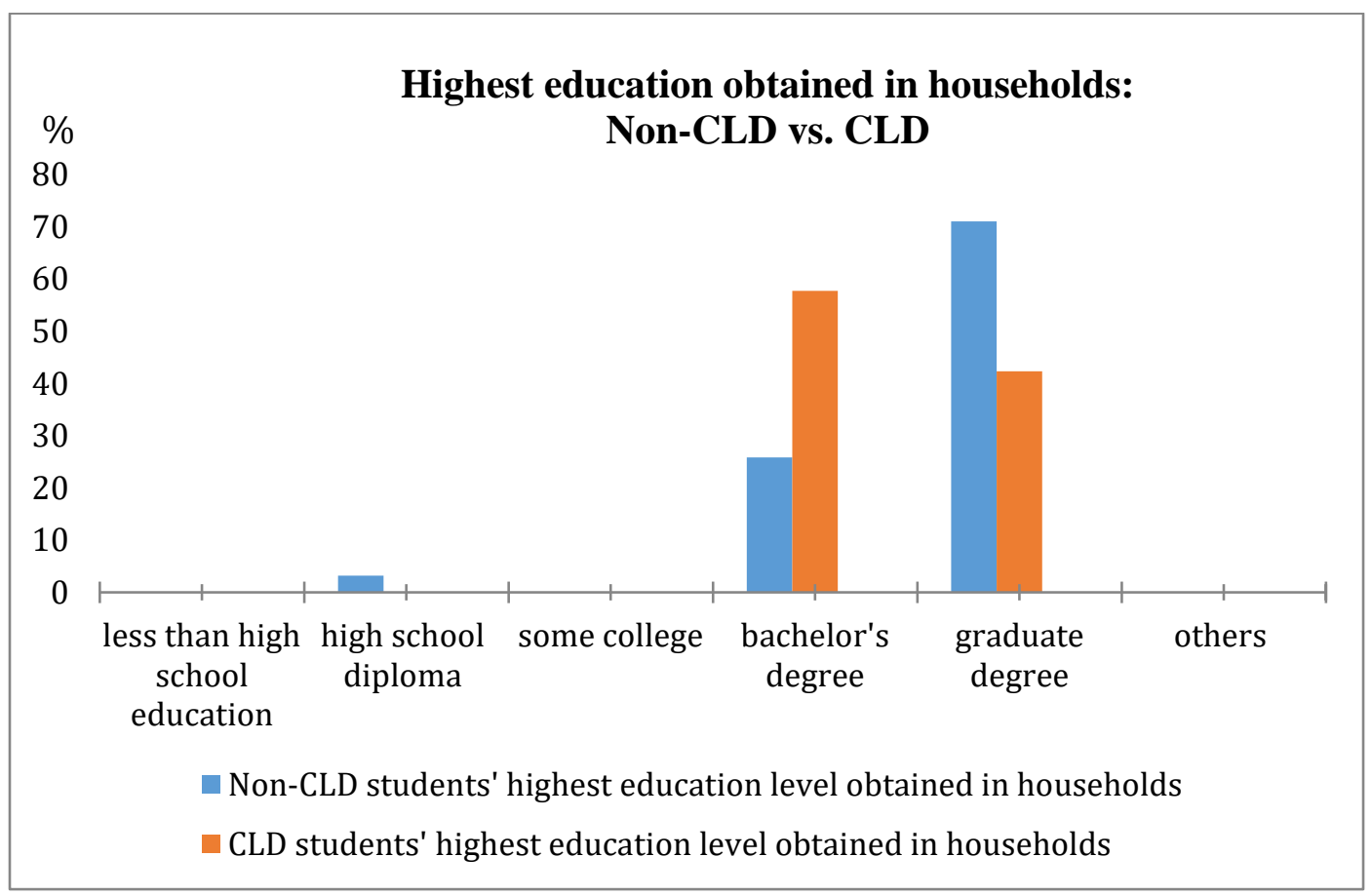

Figure 4. The highest level of education obtained in households: A comparison of non-CLD and CLD groups. 
Additionally, to obtain qualitative information regarding alumni's role models, the question of "who is your academic role model?" was posed. For this question, alumni were able to select all of their role model(s) from the choices "coworker/colleague, relative, sibling, friend, mother, father, spouse, professor/teacher." CLD alumni (15.3\%) reported that they had no role models whereas $8.7 \%$ of those who are non-CLD stated that they had no role models. Furthermore, both the CLD and non-CLD groups named various specific people (e.g., friend, family, relatives) as their academic role models. Sibling (17.6\%), friend (15.3\%), professor/teacher (14.9\%), and mother (13\%) were more frequent role models for the CLD group whereas mother (13\%), professor/teacher $(11.1 \%)$, friend $(8.7 \%)$, and father $(6.6 \%)$ were popular role models for the nonCLD group (See Figure 5).

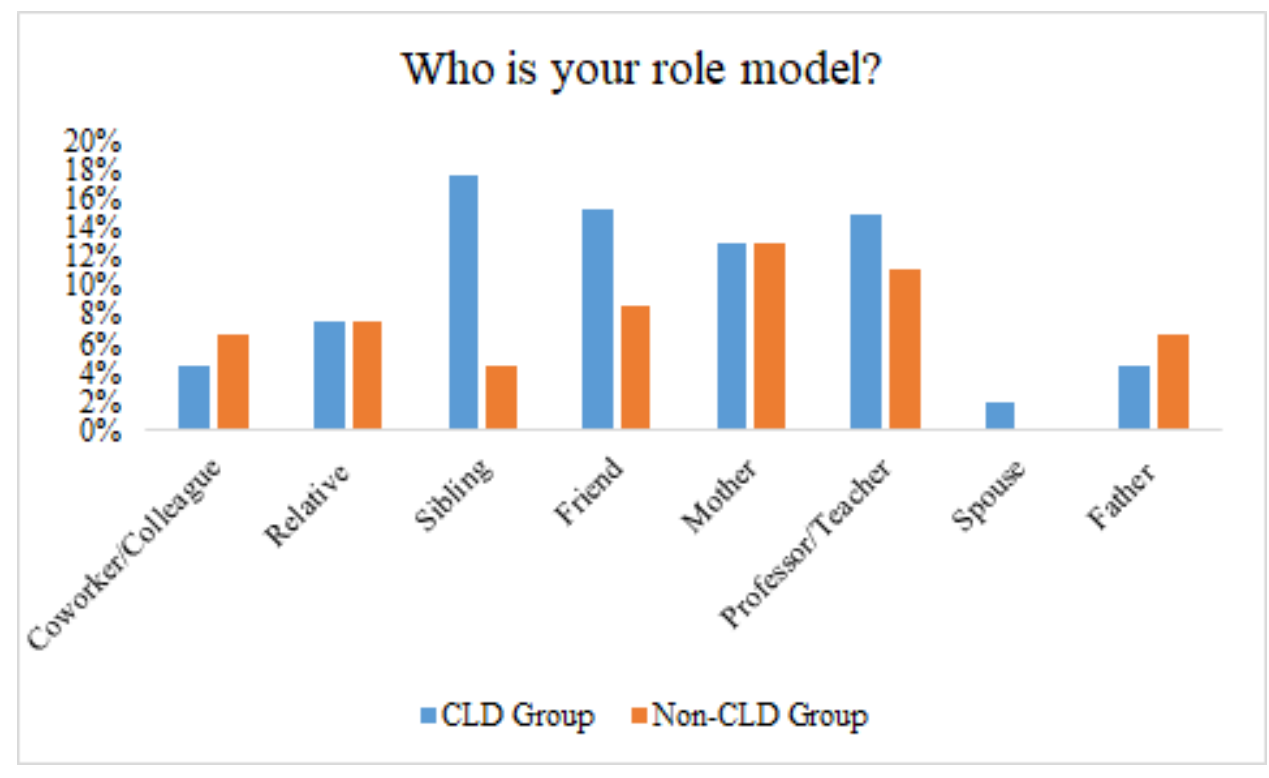

Figure 5. Academic role models of the participants. The $\mathrm{x}$-axis of the figure indicates the percentage, for each role model, reported by the participants.

\section{Support}

The majority of alumni (98\%) reported that their families support and/or encourage pursuit of graduate school. In the following sections, in addition to reviewing role model factor, the current study examined financial, emotional/moral, and/or academic support alumni have sought and/or received during undergraduate studies. It also investigated the relationship between these supports and GPA, as well as graduate admission outcomes.

Financial support. The participants reported a wide range of a total annual household income, spanning from a low of $\$ 6,000$ to a high of $\$ 200,000$. Regardless of income, the majority of the participant's families support and encourage the pursuit of a graduate degree. Moreover, the current survey included a question, "While you were completing your undergraduate degree, which of the following required a significant amount of your attention and care? (Please check all that apply)," to which the participants responded as follows: part-time job (54\%), full-time job 
(13\%), sick or elderly family members (15\%), children (8\%), family members with disability (8\%), and none $(27 \%)$. This result showed that the majority of the participants were in need of maintaining at least part-time employment while completing their undergraduate degrees.

Alumni indicated the percentage of their total tuition support contributed by family to pursue their undergraduate degrees and the data were compared between non-CLD and CLD groups (1: 0 $10 \%, 2: 20-50 \%, 3: 60-100 \%$ of tuition support). Statistical analysis indicated that alumni with CLD backgrounds received significantly less tuition support for their undergraduate studies from their family than did alumni with non-CLD backgrounds (CLD group: $M d n=1,0-10 \%, 2,20$ $50 \%$ vs. Non-CLD group: $\left.M d n=3,60-100 \%, U=168, p=.003 ; \mathrm{y}^{2}=.181\right)$. Furthermore, the data of alumni from non-CLD and CLD groups who received or anticipated receiving graduate tuition support were compared (1: 0\%, 2: 1-24\%, 3: $25-48 \%, 4: 50-74 \%, 5: 75-99 \%, 6: 100 \%)$. Alumni from CLD backgrounds received or anticipated receiving significantly less graduate tuition support than those from the non-CLD group (CLD group: $M d n=1,0 \%$ vs. Non-CLD group: $M d n=3.5$, $\left.3=25-49 \% ; 4=50-74 \%, U=130.00, p=.032 ; \eta^{2}=.106\right)$.

CSD graduate program admissions outcomes (1: not accepted, 2: currently in graduate school, and 3: completed graduate school) were scrutinized based on the amount of family tuition support, revealing that the chance of acceptance was greater for those who received greater tuition support from family ('More tuition support group': 50\% or more of tuition) as compared to others from the 'Less tuition support group' ('More tuition support group': $M d n=2, M=2.33,2$ : currently in graduate school, 3: completed graduate school vs. 'Less tuition support group': $M d n=2$, currently in graduate school, $M=1.67,1$ : not accepted, $U=138, p=.018 ; \mathrm{y}^{2}=.133$ ). It should be noted that there was no statistical difference in GPA between the 'More tuition support group' $(M d n=3.7$, $M=3.78)$ and 'Less tuition support group' $\left(M d n=3.7, M=3.63, U=279.5, p=.389 ; \eta^{2}=.015\right)$.

Emotional/moral support. Alumni were asked to report emotional/moral support sought during undergraduate and/or graduate studies and how they value emotional/moral support for academic success. The majority of alumni considered their emotional/moral support networks to be of importance to academic success (from "somewhat important" to "very important": 98\%). They were also asked from whom they sought emotional/moral support. The majority of alumni sought emotional support from a friend, family, mentor, and/or instructor, if needed (86\%: from "somewhat likely" to "likely") and reported having a relatively strong emotional/moral support system (82\%: from "somewhat strong" to "very strong"). Whereas alumni reported that they would seek emotional/moral support if needed, nearly half of alumni $(47 \%)$ have reportedly sought emotional/moral support, and $18 \%$ of alumni have not sought such support despite a reported need.

No significant difference was found in how the CLD $(M d n=2$, strong) and non-CLD $(M d n=3$, very strong, $U=204, p=.066 ; \mathrm{y}^{2}=.072$ ) alumni rated their amount of emotional/moral support, indicating both alumni groups reported greater support of individuals from whom they can seek advice. In addition, when alumni undergraduate GPA was compared to responses associated with perception of emotional/moral support, those who reported having a greater amount of emotional/moral support had a significantly better GPA $(M d n=3.69)$ than others who reported less support $\left(M d n=3.42, U=144.5, p=.014 ; \mathrm{y}^{2}=.127\right)$. Results also revealed a significant difference in admissions outcomes depending upon the level of perceived emotional/moral support. Participants who reported having 'very strong' to 'strong' emotional/moral support have 
significantly better admissions outcomes ( $M d n=2$, currently in a CLD graduate program), than others who reported having "less than strong" emotional/moral support ( $M d n=1$, not accepted/did not apply to graduate school, $\left.U=82, p=.009 ; \mathrm{n}^{2}=.201\right)$. In sum, although the current results showed that there is no difference between the amount of emotional/moral support received between the CLD and non-CLD groups, regardless of their backgrounds, when alumni received greater amounts of emotional/moral support, their academic (i.e., GPA) and admissions outcomes were better than those who received less emotional/moral support.

Academic support. The current results indicated that regardless of the CLD and non-CLD groups, most alumni reportedly sought academic help (i.e., learning center, tutoring), or reported having sought help, when warranted, during undergraduate and/or graduate studies. Although the majority (94\%) of the total participants reported that they would be "somewhat likely" to "very likely" seek academic help in the future, only $22 \%$ sought help (i.e., learning center, tutoring) when they had reported academic difficulty. A statistical result indicated no differences in GPA $(U=258, p$ $=.561 ; \mathrm{y}^{2}=.007$, Sought help: $M d n=3.60, M=3.56$ vs. Did not seek help: $M d n=3.65, M=3.59$ ) nor in admissions outcomes $\left(U=155, p=.336 ; \eta^{2}=.029\right.$, Sought help: $M d n=2, M=1.9$ vs. Did not seek help: $M d n=2, M=2.16$ ) between the groups of those who did and did not seek academic help.

Overall, the current study revealed that financial support played important roles for alumni with CLD backgrounds as compared to those from the non-CLD group. There was no difference in the amount of emotional/moral support rated between the CLD and non-CLD groups. However, the results indicated the greater amount of emotional/moral support made significant differences on their academic (i.e., GPAs) and graduate admissions outcomes while seeking academic support did not impact upon those outcomes.

\section{Discussion}

The purpose of this study was to identify factors that can contribute to the success of CLD students within CSD programs and professions. More specifically, it investigated potential factors linked to academic outcomes and/or graduate admissions of CSD majors who are from underrepresented, diverse backgrounds.

\section{Role Models and Academic Outcomes in CSD}

The current study investigated the possible effect of role models on the participants' academic outcomes. Specifically, the educational levels of the participant's immediate family were examined by comparing the highest level of education attained by participants' mothers and fathers as well as the highest education level in the household from CLD and non-CLD backgrounds. Although previous literature emphasized the importance of parents' educational backgrounds, the current study obtained information regarding the highest level of education earned in the households in order to examine whether both the CLD and non-CLD groups had similar educational role models (e.g., both had someone with college or higher educational background in their households). The present study also found that the latter group perceived a greater impact from exposure to an educational role model as compared to alumni with CLD backgrounds, and results consistently demonstrated a higher level of education obtained from members of those non- 
CLD households. According to previous research, most college students choose family members as their career role models; some may adopt family, friends, teachers, or celebrities as individuals they choose to emulate (Solomon, 1997). As found in previous research, role models could influence one's life in various ways and provide emotional/moral support by guiding, encouraging and helping one in making decisions (Nauta \& Kokaly, 2001). In the current study, improved academic outcomes (i.e., GPA) were also found among more alumni with non-CLD than CLD backgrounds, which may be a reflection of the lack of, or limited number of, academic role models among underrepresented, CLD students during undergraduate studies.

Previous research stated that children of family members serving as academic role models (Hurd et al., 2009; Karunanayake \& Nauta, 2004), and/or children of family members with higher academic degrees, tend to follow the same path (Haveman \& Smeeding, 2006). As previously found, children of parents with limited educational backgrounds may not succeed to the same extent as children of parents with college degrees. This may be due to limited financial resources as well as a lack of opportunities to prepare children for academic success and higher education (Spera et al., 2009), which may result in lower college retention rates (Chang et al., 2014).

\section{Importance of Support Systems for Academic Success}

Almost all participants reported feeling that their family supports and/or encourages pursuit of a graduate degree; however, financial challenges appear to continue to be a factor for many. For students at both undergraduate and graduate levels, alumni with CLD backgrounds received significantly less tuition support from their family than those alumni with non-CLD backgrounds; this corroborates the reported SES gap between underrepresented minority students and others (Chang et al., 2014, Seymour \& Hewitt, 1997). Considering significant differences in graduate admissions outcomes between alumni with CLD and non-CLD backgrounds, it is likely that greater financial challenges may have played a role in the less successful graduate admissions outcomes. Students from CLD backgrounds demonstrate greater financial responsibilities, more commonly resulting in a need to commit to employment (Chang et al., 2014, Seymour \& Hewitt, 1997). Haveman and Smeeding (2006) indicated that when parents have a bachelor's degree or higher, their income was greater, which subsequently allowed their children to become better prepared for college. Parents' education level and income appeared to have a significant impact on a child's accessibility to resources and opportunities for academic success (Hauser-Cram, 2009).

Beyond financial challenges experienced by underrepresented CLD alumni, the current study explored the importance of emotional/moral support networks for academic success of the alumni of the CLD and non-CLD groups. Regardless of their backgrounds both groups rated similarly the amount of emotional/moral support which they received, and the majority reported that they would seek emotional and/or academic support when they were in need of help. Although seeking greater academic support appeared to have no impact on GPA or on admissions outcomes as compared to those seeking less academic support, the positive impact of an emotional/moral support system manifested as better academic and admissions outcomes of alumni who had greater support regardless of their backgrounds (i.e., CLD vs. non-CLD). Therefore, based on the current findings, securing a strong emotional/moral support system appears to be an essential element for academic and future career success of college students. 
The authors of this following paper note that cross-cultural mentoring can be successful when mentors are culturally competent (i.e., in the absence of same-culture mentors) (Davidson \& Foster-Johnson, 2001). When one has established emotional/moral support networks, the support system could provide guidance needed for making important decisions to help overcoming challenges such as a lack of, or limited amounts of, financial resources for pursuing education which students from CLD may likely encounter (Chang et al., 2014, Spera et al., 2009).

\section{Limitations, Future Research, and Implications}

The researchers acknowledge some limitations in the current study. Data in the present study were collected in an urban setting with a small sample size for both CLD and non-CLD groups. Although the current study was distributed to a large group of alumni, due to the inability to reach many (e.g., students became difficult to access upon graduation, as many no longer had been accessing the email address which the program had on file), the response rate was low. Large, urban centers are likely to support greater diversity than more sparsely populated cities across the U.S. Therefore, the current results may not properly represent diversity as reflected in the U.S. population. Future research is suggested in which a study is conducted to include a larger sample size from multiple and varied institutions across the nation. According to the data from the U.S. Census (2018), California, Texas, Hawaii, New Jersey, New York, New Mexico, Maryland, Nevada, Florida, and Arizona are diverse in various ways. For example, Hawaii only has $22.1 \%$ White/non-Hispanic/Latino as compared to both New York and New Jersey which marked 55.8\% White/non-Hispanic/Latino. While both New York (30.7\%) and New Jersey (30.4\%) had a large number of the population who speak languages other than English spoken at home (percent of persons all 5 years + from 2012-2016), California (44\%), New Mexico (35.4\%), and Texas (35.2\%) had an even greater percentage of the populations who speak languages other than English at home than New York or New Jersey (U.S. Census, 2018). Future research should investigate differences across living environments (i.e., city, suburb, rural area) rather than limiting the study to a particular region (i.e., New York City).

Moreover, because of the survey length, the questions were not posed more than once to avoid a fatigue effect (Galesic \& Bosnjak, 2009), but this also created a situation in which it was not possible to confirm intra-rater reliability. A future study might develop a shortened list of items so that the same subset of questions can be subjected to reliability measures.

A future study could present a similar survey to undergraduate students at the time of graduation and follow those same participants longitudinally. This method will allow researchers to identify factors which might be contributing to a successful career in CSD. Additionally, more detailed information regarding gender and family structure can be obtained to explore additional factors related to diversity and non-traditional families.

Based on current findings of the importance of role models, intervention strategies would focus on efforts to hire more faculty members from CLD backgrounds so that they can serve as role models to minority students. Finding similar cultural characteristics within one's own role models could also be important to self-perception and to finding a place of self in educational settings (WinkleWagner \& McCoy, 2016). As found in the present study, many CLD students reported an instructor 
as their role models due to limited numbers of family members to serve in those roles; therefore, increased access to faculty/instructor mentors can increase diversity in the CSD professions. As previously found in the field of medicine (e.g., Cooper, Roter, Johnson, Ford, Steinwachs, \& Powe, 2003; Laviest, \& Nuru-Jeter, 2002), patients who receive care from physicians of the same race reported greater satisfaction and positive affect than physicians of other races/ethnic backgrounds and highlighted the importance of increasing diversity of physicians. Similarly, an increase of diversity and client satisfaction with services in CSD is an important issue to be addressed in future studies. Based on these current findings, having both a positive role model and a strong emotional/moral support system are prerequisite elements for academic success and improved graduate admissions outcomes. Previous research has also shown that students from low SES backgrounds have less academic preparedness even before college, which would impact academic outcomes and future success (Chang et al., 2014; Crisp, Nora, \& Taggart, 2009). Therefore, it is critical to provide guidance and moral/emotional support early (e.g., mentoring program, personalized academic advisement) to support minority students to become competitive candidates in the selective CSD application and admissions process. Since lack of financial support serves as a great barrier for CLD students, it is essential to provide financial assistance (e.g., scholarships, application fees) for those who participate in mentoring programs throughout their undergraduate studies. These approaches would allow students from underrepresented backgrounds to receive both academic and financial support to facilitate their career development and success in the CSD field. Additionally, it is recommended that CSD programs consider implementing training for current faculty and administrators so that these programs can better advocate to raise awareness and to meet the unique needs of CLD students. Implementation of a program for provision of emotional/moral support in addition to financial supports to increase retention will similarly create opportunities to increase diversity. These institutional initiatives will help to support CLD students and will ensure more diverse representation in university programs and in CSD professions.

\section{Conclusion}

The lack of diversity in CSD graduate programs and the profession could be due to various reasons. Students from low SES who have limited financial resources are largely at risk for continuing college education. Therefore, consistent financial support for admissions such as waivers of application fees for students from low SES and/or CLD backgrounds as well as tuition support for graduate education at the time of admissions decisions (e.g., tuition assistance packages to extend to program completion) would largely assist students coming from financially disadvantaged families. Waivers of application fees would help to expand the pool of CLD applicants to a larger variety of programs and would, therefore, increase the likelihood of favorable admissions outcomes for those from underrepresented groups. As previously reported, greater financial responsibilities of those from low SES groups results in the need for employment to support education, which may in turn negatively impact on academic success (e.g., GPA) (Chang et al., 2014, Seymour \& Hewitt, 1997). In general, students who are equipped with strong academic preparedness and financial support demonstrate better college retention (Chang et al., 2014). To increase the retention rate of CLD students moving from undergraduate to graduate studies, institutions can offer not only academic and financial, but emotional/moral support, as well. As revealed in the present study, finding a place in a program and establishing a sense of belonging could be critical for retention. Graduate programs can create a supportive environment which can be enhanced by offering mentorship programs and/or role models for students from 
underrepresented minorities. These multidimensional supports would be important additions for CLD students to have successful admissions and a career in the field of CSD.

\section{References}

American Psychological Association (2012). Ethnic and racial disparities in education: Psychology's contributions to understanding and reducing disparities [PDF]. Retrieved from http://www.apa.org/ed/resources/racial-disparities.aspx

American Speech-Language-Hearing Association (2002). Highlights and trends: Annual counts of the ASHA membership and affiliation, 2002 [PDF]. Retrieved from: http://www.asha.org/uploadedFiles/research/memberdata/2002MemberCounts.pdf

American Speech-Language-Hearing Association (2013). Minority student recruitment, retention and career transition practices: A review of the literature [Webpage]. Retrieved from http://www.asha.org/practice/multicultural/recruit/litreview.htm

American Speech-Language-Hearing Association (2016a). Communication sciences and disorders (CSD) education survey national aggregate data report 2014-2015 academic year [PDF]. Retrieved from: https://www.asha.org/uploadedFiles/2014-2015-CSDEducation-Survey-National-Aggregate-Data-Report.pdf

American Speech-Language-Hearing Association (2016b). Minority student recruitment and retention: preface [Webpage]. Retrieved from: http://www.asha.org/practice/ multicultural/recruit/03initiative.htm

American Speech-Language-Hearing Association. (2016c). Planning your education in communication sciences and disorders [Webpage]. Retrieved from: https://www .asha.org/Students/Planning-Your-Education-in-CSD/

American Speech-Language-Hearing Association (2017a). Highlights and trends: Member and affiliate counts, year -end 2017 [PDF]. Retrieved from: https://www.asha.org/ uploadedFiles/2017-Member-Counts.pdf

American Speech-Language-Hearing Association. (2017b). Issues in ethics: Cultural and linguistic competence [Webpage]. Available from www.asha.org/Practice/ethics/Culturaland-Linguistic-Competence/

American Speech-Language-Hearing Association (2017c). SLP health care survey 2017 [PDF]. Retrieved from: https://www.asha.org/uploadedFiles/2017-SLP-Health-Care-Survey-An nual-Salary-Report.pdf

American Speech-Language-Hearing Association (2018). Demographic profile of ASHA members providing bilingual services February 2018 [PDF]. Retrieved from: https://www.asha.org/uploadedFiles/Demographic-Profile-Bilingual-Spanish-ServiceMembers.pdf

American Speech-Language-Hearing Association (n.d.). Bilingual service delivery: Service provision for bilingual clients [Webpage]. Retrieved from https://www.asha.org /PRPSpecificTopic.aspx?folderid=8589935225\&section=Key_Issues

Association for the Study of Higher Education (2007). Social Class Effects and Multiple Identities. ASHE Higher Education Report, 33(3), 59-68. doi: 10.1002/aehe.3303

Chang, M. J., Sharkness, J., Hurtado, S., \& Newman, C. B. (2014). What matters in college for retaining aspiring scientists and engineers from underrepresented racial groups. Journal of Research in Science Teaching, 51(5), 555-580. doi: 10.1002/tea.21146

Crisp, G., Nora, A., \& Taggart, A. (2009). Student characteristics, pre-college, college, and 
environmental factors as predictors of majoring in and earning a STEM degree: An analysis of students attending a Hispanic serving institution. American Educational Research Journal, 46(4), 924-942.

Colby, S. L., \& Ortman, J. M. (2015). Projections of the size and composition of the US population: 2014 to 2060 [PDF]. United States Census Bureau. Retrieved from https://www.census.gov/content/dam/Census/library/publications/2015/demo/p251143.pdf

Cooper, L.A., Roter, D. L., Johnson, R.L., Ford, D. E., Steinwachs, D. M., \& Powe, N. R. (2003). Patient-centered communication, ratings of care, and concordance of patient and physician race. American College of Physicians, 139(11), 907-916.

Cornell University Division of Budget and Planning. (n.d.). Survey of all undergraduate students surveys [Webpage]. Retrieved from http://irp.dpb.cornell.edu/surveys/pulse-surveys

Council of Academic Programs in Communication Sciences and Disorders and American Speech-Language-Hearing Association (2015). CSD Education Survey National Aggregate Data Report: 2013-2014 academic year [PDF]. Retrieved from http://www.asha.org/uploadedFiles/2013-2014-CSD-Education-Survey-NationalAggregate-Data-Report.pdf\#page $=24$

Council of Academic Programs in Communication Sciences and Disorders and American Speech-Language-Hearing Association (2018). CSD Education Survey National Aggregate Data Report: 2016-2017 academic year [PDF]. Retrieved from: https://www. asha.org/uploadedFiles/2016-2017-CSD-Education-Survey-National-Aggregate-DataReport.pdf\#page $=55$

Davidson, M. N., \& Foster-Johnson, L. (2001). Mentoring in the preparation of graduate researchers of color. Review of Educational Research, 71 (4), 549-574.

Drummond, R. J., Senterfitt, H., \& Fountain, C. (1999). Role models of urban minority students. Psychological Reports, 84(1), 181-182. doi:10.2466/pr0.1999.84.1.181

Fay, M. P., \& Proschan, M. A. (2010). Wilcoxon-Mann-Whitney or t-test? On assumptions for hypothesis tests and multiple interpretations of decision rules. Statistics Surveys, 4, 1-39. doi: 10.1214/09-SS051

Forrest, K., \& Naremore, R. C. (1998). Analysis of criteria for graduate admissions in speechlanguage pathology. American Journal of Speech-Language Pathology, 7, 57-61. doi:10.1044/1058-0360.0704.57

Galesic, M., \& Bosnjak, M. (2009). Effects of questionnaire length on participation and indicators of response quality in a web survey. Public Opinion Quarterly, 73(2), 349-360.

Gardner, S. K. (2008). Fitting the mold of graduate school: A qualitative study of socialization in doctoral education. Innovative Higher Education, 33(2), 125-138.

Greene, K. M., \& Maggs, J. L. (2015). Revisiting the time trade-off hypothesis: Work, organized activities, and academics during college. Journal of Youth \& Adolescence, 44(8), 16231627.

Hauser-Cram, P. (2009). Education from one generation to the next: Mechanisms of mediation. Merrill-Palmer Quarterly, 55(3), 351-360

Haveman, R., \& Smeeding, T. (2006). The role of higher education in social mobility. The Future of Children, 16(2), 125-150

Harry, B. (2002). Trends and issues in serving culturally diverse families of children with disabilities. The Journal of Special Education, 36(3), 131-138.

Henry, P. (2006). Educational and career barrier to the medical profession: Perceptions of the 
underrepresented minority students. College Student Journal, 43, 429-441.

Hollingsworth, R. G., Collins, T. P., Smith, V. E., \& Nelson, S. C. (2011). Simple statistics for correlating survey responses. Journal of Extension, 49(5), 1-4.

Hurd, N. M., Zimmerman, M. A., \& Xue, Y. (2009). Negative adult influences and the protective effects of role models: A study with urban adolescents. Journal of Youth and Adolescence, 38(6), 777-789.

John, G., \& Stage, F. K. (2014). Minority-serving institutions and the education of US underrepresented students. New Directions for Institutional Research, 2013(158), 65-76.

Karunanayake, D., \& Nauta, M. M. (2004). The relationship between race and students' identified career role models and perceived role model influence. The Career Development Quarterly, 52(3), 225-234.

Kritikos, E. P. (2003). Speech-language pathologists' beliefs about language assessment of bilingual/bicultural individuals. American Journal of Speech-Language Pathology, 12(1), 73-91.

Laviest, T. A., \& Nuru-Jeter, A. (2002). Is doctor-patient race concordance associated with greater satisfaction with care? Journal of Health and Social Behavior, 43, 296-306.

Litosseliti, L. \& Leadbeater, C. (2013). Speech and language therapy/pathology: Perspectives on a gendered profession. International Journal of Language and Communication Disorders, 48(1). 90-101. doi: 10.1111/j.1460-6984.2012.00188.x

Nauta, M. M., \& Kokaly, M. L. (2001). Assessing role model influences on students' academic and vocational decisions. Journal of Career Assessment, 9(1), 81-99.

New York City Department of Education (2015). New York City Department of Education Department of English Language Learners and Student Support School Year 2013-2014 Demographic Report [PDF]. Available from https://tinyurl.com/ycls84p9

Pace, C. R., \& Kuh, G. D. (1998). College student experience questionnaire [PDF]. Retrieved from https://dpb.cornell.edu/documents/1000093.pdf

Polovoy, C. (2014). Student's say: Craft a stand-out application. The ASHA Leader, 19, 54-55. doi:10.1044/leader.SSAY.19012014.54

Saenz, T., Wyatt, T., \& Reinhard, J. (1998). Increasing the recruitment and retention of historically under-represented minority students in higher education: A case study. American Journal of Speech-Language Pathology, 7(3), 39.

Serbin, L., Stack, D., \& Kingdon, D. (2013). Academic success across the transition from primary to secondary schooling among lower-income adolescents: Understanding the effects of family resources and gender. Journal of Youth and Adolescence, 42(9), 13311347.

Seymour, E., \& Hewitt, N. M. (1997). Talking about leaving: Why Undergraduates leave the sciences. Boulder, $\mathrm{CO}$ : Westview Press.

Simon, D. J. (1993). Increasing the academic pool of minority students for higher education: A literature review: A report to the R. F. P. \#92-3 team. Richmond, VA: Metropolitan Educational Research Consortium.

Smeding, A., Darnon, C., Souchal, C., Toczek-Capelle, M., \& Butera, F. (2013). Reducing the socio-economic status achievement gap at University by promoting mastery-oriented assessment. PloS One, 8(8), E71678.

Solomon, R. P. (1997). Race, role modelling, and representation in teacher education and teaching. Canadian Journal of Education / Revue Canadienne De L'éducation, 22(4), 39 395. doi:10.2307/1585791 
Spencer, B., \& Castano, E. (2007). Social class is dead. Long live social class! Stereotype threat among low socioeconomic status individuals. Social Justice Research, 20(4), 418-432.

Spera, C., Wentzel, K., \& Matto, H. (2009). Parental aspirations for their children's educational attainment: Relations to ethnicity, parental education, children's academic performance, and parental perceptions of school climate. Journal of Youth and Adolescence, 38(8), 1140-52.

Steffani, S. A., \& Slavin, D. (1997). The survey of the graduate admission process. Contemporary Issues in Communication Science and Disorders, 24, 1-11.

Tan, D. L. (1995). Perceived importance of role models and its relationship with minority student satisfaction and academic performance. NACADA Journal, 15(1), 48-51. doi:10.12930/02 71-9517-15.1.48

Thomas, K. M., Willis, L. A., \& Davis, J. (2007). Mentoring minority graduate students: Issues and strategies for institutions, faculty, and students. Equal Opportunities International, 26(3), 178-192.

United States Census Bureau (2010). Our surveys and programs [Webpage]. Retrieved from: https://www.census.gov/en.html

United States Census Bureau (2012). U.S. Census Bureau projections show a slower growing, older, more diverse nation a half century from now [Webpage]. Retrieved from: https://www.census.gov/newsroom/releases/archives/population/cb12-243.html

United States Census Bureau (2013). Language use in the United States: American community survey reports [PDF]. Retrieved from: https://www.census.gov/prod/2013pubs/ acs-22.pdf

United States Census Bureau (2017). Income and poverty in the United States: 2016 [Webpage]. Retrieved from: https://www.census.gov/library/publications/2017/demo/p60-259.html

United States Census Bureau (2018). Quick Facts United States [Webpage]. Retrieved from: https://www.census.gov/quickfacts/fact/table/US/PST045217

United States Department of Education (2013). National Center for Education Statistics, Table 219.30. Public high school graduates, by racelethnicity: 1998-99 through 202324 [Webpage]. Retrieved from http://nces.ed.gov/programs/digest/d13 /tables/dt13_219.30.asp

Winkle-Wagner, R. \& McCoy, D. L. (2016). Entering the (postgraduate) field: Underrepresented students' acquisition of cultural and social capital in graduate school preparation programs. Journal of Higher Education, 87(2), 178-205. doi: 10.1353/jhe.2016.0011

Zhang, D., Hsu, H., Kwok, O., Benz, M., \& Bowman-Perrott, L. (2011). The impact of basiclevel parent engagements on student achievement: Patterns associated with race/ethnicity and socioeconomic status (SES). Journal of Disability Policy Studies, 22(1), 28-39. doi: $10.1177 / 1044207310394447$ 


\section{Appendix}

\section{Survey questions.}

How old are you? Please enter your age in years. (fill-in)

Gender: (multiple choice)

What is your ethnicity? Please select all that apply. (multiple choice)

Did you attend graduate school in SLP or AuD? (yes/no)

What is your total annual household income (including your wages if you are employed)? (fill-in)

What is your mother's highest level of education? (multiple choice)

What is your father's highest level of education? (multiple choice)

What is the highest level of education obtained in your household? (multiple choice)

Who has earned the highest level of education in your household? (multiple choice)

To what extent does your family support and/or encourage attending graduate school? (Likert scale)

What percent of your total tuition for your undergraduate degree did your family provide? (fill-in)

For graduate school tuition approximately what percent would/did your family provide? (multiple choice)

What was your cumulative GPA upon completion of your undergraduate CSD degree? (fillin)

How would you rate the strength of your emotional/moral support system? (i.e. friends, spouses, teachers, family that you can talk to about stress, issues, or seek advice, encouragement, etc.) (Likert scale)

How important did you feel having an emotional/moral support system has been for your academic success? (Likert scale) 
Have you previously sought academic help (i.e., tutoring, Learning Center, individual instructor advisement, etc.)? (multiple choice)

How likely are you to seek academic help in the future, if needed? (Likert scale)

Have you previously sought emotional support (i.e., personal counseling, from a friend, instructor, professional, family member, mentor, etc.)? (multiple choice)

How likely are you to seek emotional support if needed (this could be from a friend, instructor, professional, family member, mentor, etc.)? (Likert scale)

Who is your academic role model? Please select all that apply if you have more than one. (multiple choice)

Which graduate programs did you apply to? (fill-in)

Which graduate programs were you accepted to? (fill-in) 